very uncommonly reported in the absence of a lumbar puncture having been carried out.

The current practice of more intensive care of the newborn, with lumbar puncture being a not infrequent part of 'infection screens' carried out by junior staff, may lead to the occurrence of more implantation epidermoid tumours in the future. We strongly recommend the use of the smallest lumbar puncture needle available with the stilette in place until the skin has been punctured. The stilette can then be removed and the needle advanced until the dura is penetrated and cerebrospinal fluid obtained.
References

${ }^{1}$ Shaywitz BA. Epidermoid spinal cord tumours and previous lumbar puncture. J Pediatr 1972;80:638-40.

2 Lissauer T. Practical procedures in children (2). Hospital Update 1982:1545-53.

3 Ingraham FD, Matson DD. Neurosurgery of infancy and childhood. Springfield: Charles C Thomas, 1954.

${ }^{4}$ Rand RW, Rand CW. Intraspinal tumors of childhood. Springfield: Charles C Thomas, 1960.

Correspondence to Dr A W Craft, The Royal Victoria Infirmary, Queen Victoria Road, Newcastle upon Tyne NE1 4LP.

Received 18 June 1985

\title{
Obtaining parental consent-opting in or opting out?
}

\section{MUTCH AND R KING}

\author{
National Perinatal Epidemiology Unit and Oxford Region Child Development Project, Radcliffe \\ Infirmary, Oxford
}

SUMMARY In a population based project aimed at identifying children with specified disabilities within a health region, there was, rightly, concern about the transfer of data on named children across health district boundaries. Two methods of obtaining parental consent for this process were tested. High recruitment rates were achieved using an 'opting out' approach.

Throughout the health services much information about patients is collected, for several reasons. First and foremost, information is collected about specific individuals to assist in the diagnosis and management of their illnesses. Subsequent communication of this information between different arms of the health service requires the naming of the specific individuals.

Secondly, information is collected about groups of patients for the purpose of describing patterns of clinical practice, or for planning future health services. Such information does not need to identify specific individuals in order to be useful.

The provision of health services for children poses a particular problem. The emphasis is on preventive and screening measures for all children and information is required not just about those who are ill. The health services themselves must initiate the contact, obtaining information from the time of birth on all children identified by name, date of birth, and place of residence.

When screening programmes show potential problems and diagnostic referral is indicated, information passes from the preventive to the diagnostic and therapeutic services, without concern for confidentiality because it is considered to be in the ultimate best interest of the individual patient. Prior discussion, however, concerning the acceptability of the referral should have taken place with the parents.

The routine examinations of infants by health visitors has the tacit approval of the parents because they bring their child to a clinic or allow access to them at home.

In the Oxford Region Child Development Project, health visitors apply standardised screening procedures to all infants weighing less than $2000 \mathrm{~g}$, and to those who required special care in the neonatal period for more than 24 hours. The results are relayed centrally to the project office, together with the results of diagnostic referral, so that the number of individual children with specific disabilities in this geographically defined population can be documented. Because of our concern to acknowledge the confidential nature of this information, and because it involves transfer of information from the health services to a research project, it was important to seek the permission of parents for this transfer according to the principles set out in the report of the British Medical Association's Central Ethical Committee. 1

Anecdotal evidence (Alberman, Stanleypersonal communication) suggested that an 'opting out' approach to determine parental permission achieved a higher recruitment rate than 'opting in'. 
The pilot study for this project compared the efficiency of these two approaches in achieving recruitment and in its acceptability to parents.

\section{Method}

The health district ethics committee approved the pilot study and paediatricians and nursing staff of the special care nursery agreed to participate.

The study was carried out in one health district over a 12 week period. As children to be prospectively screened in this project will mostly have received their initial neonatal care in a special care nursery, permission for enrolment was sought at this juncture.

Two forms of letters to parents were used. The first letter, following a brief description of the project, asked parents for signed permission for their child to be included in the study-an 'opting in' approach; the second asked parents to sign only if they objected to their child being enrolled-the 'opting out' approach. Tear off slips and freepost envelopes were supplied to facilitate response.

Prior to the child's discharge from hospital, parents were given these two types of letter on alternate weeks. Nursing staff were careful not to apply any pressure, reassuring parents that they would still have contact with their health visitor even if they did not wish to enrol their child.

\section{Results}

Eighty three eligible infants were admitted to the nursery during the 12 week period. Of these, eight infants died and six infants were accidentally omitted. The recruitment rate (Table) was $97 \%$ from the 'opting out' and $79 \%$ for the 'opting in' approach.

Parental reaction. Most parents were pleased at the prospect of a continuing interest in their babies. A few were concerned that enrolment would entail special journeys for assessment, or that their babies would have blood tests. Ten parents (33\%) receiving the 'opting out' letter were uncertain
Table Recruitment rate

\begin{tabular}{|c|c|c|c|c|c|}
\hline Letter $A$ (opting in) & No & $(\%)$ & Letter B (opting out) & No & $(\%)$ \\
\hline No letters distributed & 39 & $(100)$ & No letters distributed & 30 & $(100)$ \\
\hline $\begin{array}{l}\text { Replies received: } \\
\text { Consenting } \\
\text { Refusing }\end{array}$ & $\begin{array}{r}34 \\
31 \\
3\end{array}$ & $\begin{array}{r}(87) \\
(79) \\
(8)\end{array}$ & $\begin{array}{l}\text { Implicit consent } \\
\text { (no reply) }\end{array}$ & 19 & (63) \\
\hline No reply & 5 & (13) & $\begin{array}{l}\text { Replies received: } \\
\text { Consenting } \\
\text { Refusing }\end{array}$ & $\begin{array}{r}11 \\
10 \\
1\end{array}$ & $\begin{array}{r}(36) \\
(33) \\
(3)\end{array}$ \\
\hline Recruitment rate & & $79 \%$ & Recruitment rate & & $97 \%$ \\
\hline
\end{tabular}

whether by not signing the tear off slip they were consenting to enrolment, and they changed the wording of the response slip to ensure that their child was included.

Staff reaction. Discussion of the letter gave parents the opportunity to talk to staff about their concerns for their children so that all communications between parents and staff benefited.

\section{Discussion}

The option of refusal was taken up by a small minority of parents with both types of letter. The 'opting out' approach achieved the greater recruitment rate, but parents had more difficulty in knowing how to respond to it. The nursing staff suggested that some parental worries would be allayed if the letter emphasised the routine nature of the examination and specifically stated that there were to be no blood tests. The 'opting out' letter was accordingly redesigned. It has been used in the main project for a year and is achieving 97 to $98 \%$ recruitment rates across the health region.

\section{Reference}

1 Handbook of Medical Ethics. London: British Medical Association;1980:31-2.

Correspondence to Dr L Mutch, National Perinatal Epidemiology Unit, Radcliffe Infirmary, Oxford OX2 $6 \mathrm{HE}$.

Received 17 June 1985 